\title{
Maternal Psychological Absence and Toddlers' Social-Emotional Development: Interpretations From the Perspective of Boundary Ambiguity Theory
}

\author{
ERIKA L. BOCKNEK* \\ HOLLY E. BROPHY-HERB \\ HIRAM FITZGERALD** \\ KATHLEEN BURNS-JAGER ${ }^{\dagger}$ \\ MARSHA T. CAROLAN
}

The current study tests a novel latent construct reflecting psychological absence and examines its relations with maternal depression, mother-toddler interactions, and toddlers' social-emotional outcomes in a low-income sample $(\mathrm{N}=2,632)$. Structural equation modeling confirmed a psychological absence construct and revealed that psychological absence, measured at the child's 36-month birthday-related assessment, is a significant predictor of children's social-emotional development at 36 months, mediated by motherchild interaction. Results are interpreted within a boundary ambiguity framework.

Keywords: Boundary Ambiguity; Psychological Absence; Social-Emotional Development

Fam Proc 51:527-541, 2012

$\mathrm{B}$ oundary ambiguity (hereafter referred to as BA) is "a state in which family members are uncertain in their perceptions about who is in or out of the family and who is performing what roles and tasks within the family system" (Boss \& Greenberg, 1984, p. 536). Such roles and tasks, indicators of family boundaries, include the physical and psychological processes relevant to particular family roles. Boss (1977) articulated BA theory and theoretically defined the construct of psychological absence as a form of BA. Psychological absence (hereafter referred to as PA), the focus of the current study, is conceptually defined as a family member's physical maintenance of his/her family role while behaving as absent at the level of psychological and emotional processes.

A wide body of literature characterizes depressed mothers in this way. That is, depressed mothers maintain the role of mother physically and symbolically, but they are frequently withdrawn, detached, and otherwise psychologically and emotionally absent (Lovejoy, Graczyk, O’Hare, \& Neuman, 2000; Stein et al., 1991). Research has examined the associations between maternal depression and interactional patterns between mothers and young children, but studies alternately find that negative patterns similar to the currently hypothesized components of PA, such as insensitive and detached parenting, are

\footnotetext{
*Department of Psychiatry, University of Michigan, Ann Arbor, MI.

${ }^{\dagger}$ Human Development and Family Studies, Michigan State University, East Lansing, MI.

**University Outreach and Engagement, Michigan State University, East Lansing, MI; Department of Psychiatry, Michigan State University, East Lansing, MI.

Correspondence concerning this article should be addressed to Erika London Bocknek, University of Michigan, Department of Psychiatry, Ann Arbor, MI. E-mail: ebocknek@med.umich.edu.
} 
predictive of poor outcomes for children independently from maternal depression (e.g., Leckman-Westin, Cohen, \& Stueve, 2009) and comorbid with depression (e.g., Leigh \& Milgrom, 2008; Lovejoy et al., 2000). Still other research has not found associations between maternal depression and these behavioral constructs (Chazan-Cohen et al., 2007). Depressed mothers might be either withdrawn or intrusive and controlling, indicating two very different parenting styles related to depression (Field, 2010). Despite known associations between depression and children's maladjustment, the need to understand how maternal depression affects children's development reflects a gap in the literature (Ashman, Dawson, \& Panagiotides 2008; Maughan et al., 2007). We first address maternal depression, then provide a rationale for the hypothesized indicators of PA, and subsequently discuss attachment theory, each of which reflects processes consistent with systems theory.

\section{Maternal Depression}

Parental depression is a known risk factor for children (e.g., Campbell et al., 2004; Feng et al., 2008; Field, 2010; Goodman et al., 2011; Maughan, Cicchetti, Toth, \& Rogosch, 2007), with children in low-income populations at higher risk of having depressed primary caregivers (Kiernan \& Huerta, 2008; Peden, Rayens, Hall, \& Grant, 2004). Depressed parents may be behaviorally withdrawn or intrusive, and maternal sensitivity may moderate the impact of depressive symptoms on child development (Campbell et al., 2004). The quality of mother-child interactions mediates relations between maternal depression and children's outcomes (Feldman et al., 2009; Foster, Garber, \& Durlak, 2008). Maternal depression and the associated risks likely reflect a systemic pattern of emotional absence, suggesting that a systems-based theoretical model, such as BA theory, may provide a useful explanatory model. A metaconstruct such as PA explains a particular context of maternal depression, helping to make sense of some of the discontinuities in the extant literature. In the current study, we hypothesize that PA, defined by lack of empathy, parental distress, and detachment, is a construct unique from, but correlated with, maternal depression.

\section{Psychological Absence}

Psychological absence is associated with emotional and psychological pathology for the family member who experiences the loss, such as might be the case for the partner or adult child of an Alzheimer's patient (e.g., Boss, Caron, Horbal, \& Mortimer, 1990; Thomas, Clement, Hazif-Thomas, \& Leger, 2001). However, the construct of PA has not been quantitatively studied in regard to the relationships between parents and their infants and toddlers.

The hypothesized PA latent construct is essentially a metaconstruct of correlates of insensitive and inattentive parenting; we suggest that these correlates represent a broader construct based on the affective and cognitive components of BA (via the Boundary Ambiguity Scale; BAS; Boss, 1977). Consistent with the BA framework (Carroll, Olson, \& Buckmiller, 2007), PA reflects the mother's emotional distancing from the child and immobilization in engaging the child, operationalized in this study as distress in the parenting role, lack of empathy for the child, and maternal detachment during motherchild interactions.

The hypothesized indicators of PA are clearly linked with children's social-emotional outcomes. Parenting stress among low-income mothers is related to young children's reduced social-emotional competence (Anthony et al., 2005). Mothers' lack of empathy for their children is associated with children's less optimal social-emotional development (Bavolek, 1989). Maternal detachment in infancy and toddlerhood contributes to reduced 
social-emotional competence in 3-year-olds, particularly if children have insecure or mixed attachment histories (Belsky \& Fearon, 2002), and to trajectories of internalizing behaviors (Sterba, Prinstein, \& Cox, 2007). Theoretically, the three indicators of PA reflect processes expected to characterize mothers' emotional unavailability. Maternal distress compromises the psychological processes of mothers, contributing to inaccurate perceptions of their children and impaired parenting (Deater-Deckard, Petrill, Thompson, \& DeThorne, 2005). Lack of empathy aligns theoretically with detached maternal behavior in which there is little shared emotional meaning between parent and child (Ainsworth, 1969). Because toddlers rely on their mothers' emotional availability as they develop competencies (Brownell \& Kopp, 2007; Raikes, Robinson, Bradley, Raikes, \& Ayoub, 2007), PA likely reflects a severe interruption of normative early developmental processes.

Boundary ambiguity theory, based on a symbolic interactionist perspective (Boss, 2007; Boss, Greenberg, \& Pearce-McCall, 1990), emphasizes the ways in which individuals perceive dissonance in the physical and psychological presence of a family member, promoting family-level disorganization and contributing to individual dysfunction (Boss, 2004, 2006). Focht-Birkerts and Beardslee (2000) demonstrate that a family's ability to process affect, or assign coherent meaning to affective experiences, may ameliorate the negative effects children experience when parents are depressed and psychologically absent. Meaning making is central to conceptualizing the process through which PA impacts outcomes. Meaning making, in essence, refers to the ways in which one person in a relationship might perceive and make sense of discontinuities.

\section{Attachment Theory and Meaning Making}

Attachment theory supports the notion that children derive meanings about themselves through parent-child interactions, determining coconstructed paradigms of self and self in relationships (Bowlby, 1969/1973/1980; Crockenberg \& Leerkes, 2000). Attachment theory is particularly helpful in this study as infants and toddlers are unable to verbally articulate understandings about their mothers' PA and its impact on their own sense of self and development. BA theory and attachment theory have been successfully integrated in previous work (e.g., Madden-Derdich \& Arditti, 1999), and we utilize attachment theory in the current study as a supplementary framework to BA. Young children's behaviors are shaped by their perceptions of social interactions (and the meanings they assign to those perceptions) (Ackerman \& Dozier, 2005; Kochanska, 2001). The development of intersubjectivity underscores the ways in which the parent and infant coconstruct meaning in mutual regulatory and empathic processes (Trevarthen \& Aitken, 2001) and is a central function of the early mother-child relationship (Bornstein \& Tamis-LeMonda, 2004). Children's behavioral reflections of relational dysfunction in the parent-child relationship are well documented in clinical models (Lieberman \& Van Horn, 2009). We hypothesize that maternal PA represents a form of BA that disrupts toddlers' abilities to derive healthy meanings about self and other. We expect that these disruptions would be behaviorally reflected in toddlers' compromised social-emotional development. Research describing BA and young children is critical given existing scholarship demonstrating the ways in which children's early relationship experiences inform development (Bowlby, 1969/1973/1980; Crockenberg \& Leerkes, 2000).

\section{The Current Study}

The existing research literature suffers from lack of knowledge in three related areas. First, more work is needed in operationalizing theoretical constructs hypothesized to articulate the processes through which early disruptions in young children's meaning making about self and other may occur. When a family member is "there, but not there," the 
"ambiguity [inherent in that type of disconnection] freezes the grief process and prevents cognition, thus blocking coping and decision-making processes" (Boss, 2007). These concepts pertinent to BA, including shared meaning making via emotional interactions, reflect relevant processes in the mental health of toddlers and parents in relationship together.

Second, although there is ample research on the hypothesized components of PA (as noted above), there is scant research on how PA, a type of BA, may affect early social-emotional development. BA has most often been studied as an extension of family systems theories in the examination of family functioning among adults and older children. A limited number of studies have presented empirical findings regarding the impact of BA on older children, demonstrating the negative impact of family BA on children's attachment security (e.g., Madden-Derdich \& Arditti, 1999), adjustment (e.g., Buehler \& Pasley, 2000; Rosenberg \& Guttmann, 2001), and mental health (e.g., Bocknek, Sanderson, \& Britner, 2009; Taanila, Laitinen, Moilanen, \& Jarvelin, 2002).

Study purposes were to: (1) test a latent construct measuring PA; and (2) examine the relationship between PA and children's social-emotional outcomes (orientation and engagement and emotion regulation) at age 3 years. The analytic strategy utilized in the current study to measure PA retained the cognitive and affective dimensions of meaning making critical to the BAS (Boss, 1977). As perception is so central to the measurement of BA, the mother's perception of self in the context of her parenting role was included. Although this is different from the perception of the survivor of an ambiguous loss, in this case the child, the perception of the family via the primary caregiver provides important information relevant to healthy family adaptation and functioning (Lavee, McCubbin, \& Patterson, 1985). Observations of the behavioral manifestations of PA were included to complement data on the mothers' perceptions. PA was hypothesized to significantly negatively predict the quality of positive mother-toddler interaction and toddlers' social-emotional outcomes. Positive parent-child interaction was hypothesized to partially mediate relations between maternal PA and outcomes. Hypotheses related to parent-child interaction are supported by the literature that demonstrates that positive interactions between mothers and children buffer the effects of risk factors, including maternal psychopathology, on young children (Feng et al., 2008; Leckman-Westin et al., 2009). Depressive symptoms were hypothesized to positively correlate with PA.

Four covariates known to be associated with early development were employed. Maternal living arrangements were included as young children experience differential social-emotional outcomes based on parental marital status and the presence of alternative caregivers (e.g., Aronson \& Huston, 2004). Married parents may be more likely to demonstrate a sense of parental satisfaction (Rogers \& White, 1998), suggesting that other family relationships can impact the parent-child relationship and boundary construction. Children's temperament was included given associations between temperament and regulatory skills (Rothbart \& Derryberry, 1981) and between temperament and parenting (Thomas \& Chess, 1977). Early Head Start (EHS) is known to impact parenting and child outcomes (Love et al., 2005), and EHS program participation was included in the model. Cumulative demographic risk, via a risk index utilized effectively elsewhere (e.g., Raikes et al., 2006), was utilized as the amount of risk varied in the sample.

\section{METHOD}

This study reflects a secondary analysis of data from the National Early Head Start Research and Evaluation Study (EHSRE; Love et al., 2005), in which data were collected from 3,001 children and their primary caregivers (99\% were mothers) who were income eligible for EHS. Participants were randomly assigned to the EHS program $(n=1,503)$ or 
comparison ( $n=1,474)$ groups. Data collection occurred in the home near the children's 14-month, 24-month, and 36-month birthdays, during the children's transition to prekindergarten, and in fifth grade. Data collection methods included an oral parent interview, direct child assessment, and observation of parent-child interactions. All key study variables reflect the 36-month birthday-related assessment. Covariates were assessed at EHSRE enrollment when children were less than 12 months of age with the exception of temperament, which was measured at children's 14-month birthday-related assessment.

Given this study's focus on family organization, homogeneity in the primary caregiver role clarifies data interpretation. Only families in which the primary caregivers were biological mothers were included. Data from 328 families without data on any key study instrument were excluded. Families excluded from the study have significantly lower income $(t=-2.40, p<.05)$ and higher cumulative risk $(t=2.89, p<.05)$ at baseline, compared with families included in the current study. This finding, common to other studies utilizing EHSRE data (e.g., Chazan-Cohen et al., 2007), together with the lack of outcome data to test for associations between missingness and study variables, suggests this group of missing data is nonignorable; data cannot be reasonably imputed. The final sample size was 2,632 families. Power analyses using NIESEM software (Dudgeon, 2003), based on the algorithm by MacCallum, Browne, and Sugawara (1996), indicated adequate sample size.

Fifty-one percent of children in the sample were boys ( $n=1,334 ; n=1,298$ girls) and were, on average, 37.48 months old $(S D=1.96 ; \min =33.24, \max =54.10)$ at the 36-month birthday-related assessment. In the current sample, 968 (38\%) families were described as White; 894 (35\%) were described as Black; 602 (23\%) were described as Hispanic; and 116 (5\%) families were described as "other," including Asian-American, Arab-American, and Native-American families.

Extensive attrition analyses were conducted within the sample of 2,632 to examine patterns of missingness. There were no significant differences between groups based on missingness related to key predictor or outcome variables. Data were determined to be missing at random, and imputation proceeded. Missing data were imputed prior to analyses using the expectation maximization (EM) algorithm (Dempster, Laird, \& Rubin, 1977). Scholars agree that FIML, another potential approach, and EM should yield similar results and have largely trivial differences in bias and efficiency (Enders, 2006; Schafer \& Graham, 2002).

\section{Measures}

See Table 1 for descriptive information of main study variables and Table 2 for bivariate associations. Coding of play tasks was conducted by multiethnic teams of graduate students (different from those coding emotion regulation) trained to a criterion level of $85 \%$ agreement (exact or within 1 point) on all 7-point scales with intermittent reliability checks performed on 15-20\% of each coder's weekly videotape assignments. Coders were unaware of participants' scores on self-report measures (Love et al., 2005). Love et al. (2005) report alphas of .70 and above on all coded outcome measures.

\section{Indicators of PA and Depressive Symptoms}

\section{Parenting distress}

Parenting distress was measured by total scores on the Parenting Distress subscale (12 items) of the 36-item Parenting Stress Index-Short Form (PSI; Abidin, 1995). This subscale measures the level of distress a parent feels in his/her role as parent ( $\alpha$ ranged from .81 to .90). Items include, "You feel trapped by your responsibilities as a parent," and "You often have the feeling that you cannot handle things very well." 
TABLE 1

Descriptive Statistics for Main Study Variables

\begin{tabular}{lcccrr}
\hline Variable & Mean (SD) & Minimum & Maximum & Skewness & Kurtosis \\
\hline Parental depression & $4.95(5.19)$ & .00 & 34.00 & 1.82 & 4.68 \\
Psychological absence & & & & & \\
$\quad$ Parenting distress & $19.12(5.49)$ & 12.00 & 43.00 & .85 & .66 \\
$\quad$ Lack of empathy & $3.06(.67)$ & 2.00 & 5.00 & .59 & -.06 \\
$\quad$ Parental detachment & $1.14(.23)$ & 1.00 & 3.00 & 4.27 & 21.88 \\
Positive parent-child interaction & & & & & \\
$\quad$ Parental supportiveness & $4.11(.55)$ & 2.00 & 6.33 & .15 & 3.26 \\
$\quad$ Child engagement & $5.01(.57)$ & 3.00 & 7.00 & -.77 & 3.50 \\
Child outcomes & & & & & \\
$\quad$ Emotion regulation & $3.97(.71)$ & 1.43 & 5.00 & -.81 & .67 \\
$\quad$ Orientation and engagement & $3.85(.73)$ & 1.60 & 5.00 & -.50 & -.32 \\
\hline
\end{tabular}

\section{Parental lack of empathy}

Parental lack of empathy was measured by the total scores on the 10-item Lack of Empathy subscale of the Adult-Adolescent Parenting Inventory (AAPI) (Bavolek, 1984; $\alpha=.76)$. Bavolek (1984, p. 6) defines empathy as "awareness of a child's needs [that] entails the ability of the parent to understand the condition or state of mind of the child without actually experiencing the feelings of the child."

\section{Parental detachment}

Parental detachment was coded from a free play task adapted from the NICHD Early Child Care Research Network (Love et al., 2005). During the 10-minute play task, the mother was provided three cloth bags of toys and invited to play with her child however she wished as long as she used the bags in a specified order. The vague directions of this task have the intention of eliciting naturally occurring behaviors (Love et al., 2005). Parental detachment includes behaviors such as inattention to the child and a seeming lack of engagement and awareness; mothers were rated on a 7-point scale. Higher scores indicate greater detachment.

\section{Depressive symptoms}

The Center for Epidemiological Studies-Depressive Symptoms (CES-D) short form measures symptoms of depressive symptoms and includes 12 items (Radloff, 1977; Ross, Mirowsky, \& Huber, 1983). The scale does not diagnosis depressive symptoms, but it does discriminate between depressed and nondepressed respondents. Items include restless sleep, lack of energy, and poor appetite $(\alpha=.88)$. Scores range from 0 to 36 .

\section{Measures of Positive Parent-Child Interaction Assessed}

\section{Parental supportiveness}

Parental supportiveness was coded from the semistructured play task described above and reflected a composite measure of three highly correlated subscales: parental sensitivity (mother takes the child's perspective, accurately perceives the child's cues, and responds appropriately), cognitive stimulation (mother demonstrates teaching behaviors to increase the child's abilities), and positive regard (mother demonstrates love, respect, admiration). Behaviors were rated on a 7-point scale. An average score was computed across the three components. 


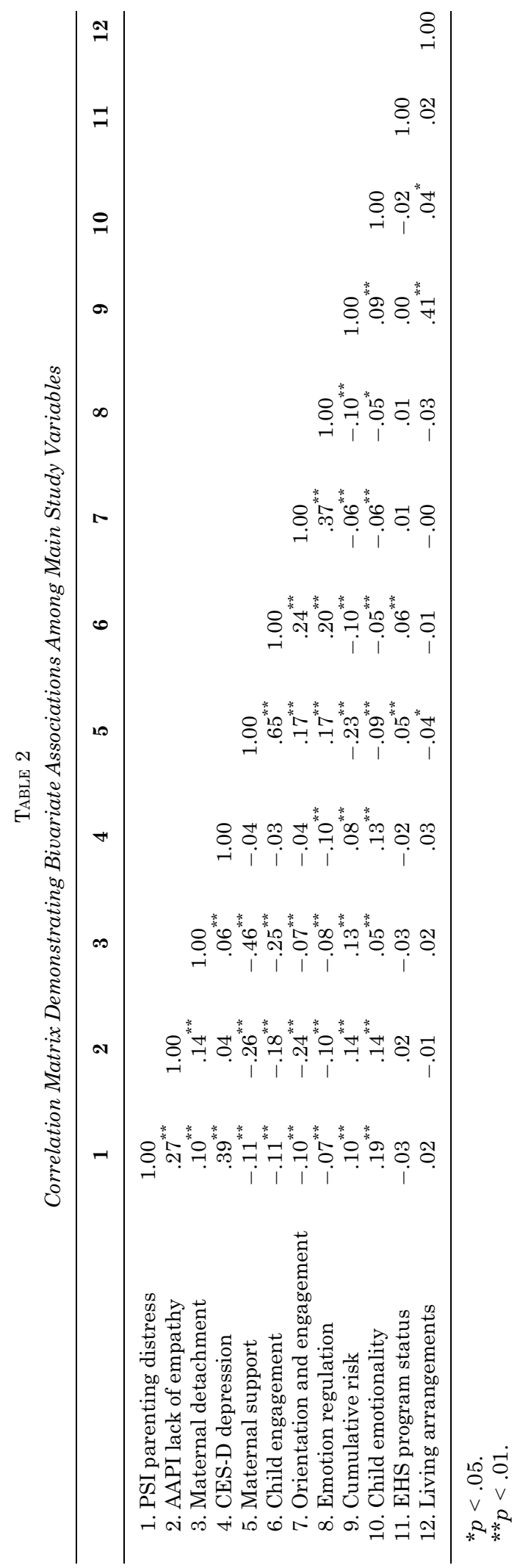




\section{Child engagement}

Child engagement was coded from the play task described above, measuring the degree to which a child shows, initiates, and/or maintains contact with the parent over the course of the task. Engagement was scored on a scale of 1-7. Higher scores indicated greater engagement.

\section{Measures of Child Outcomes}

\section{Social-emotional outcomes}

The behavior rating scales of the Bayley Scales of Infant Development, 2nd ed. (Bayley, 1993), assessed the child's behavior during the Bayley Mental Development Index assessment, yielding two summary subscales: orientation and engagement and emotion regulation, which have been used extensively as indicators of social-emotional development (e.g., Chazan-Cohen et al., 2007; Vogel, Bradley, Raikes, Boller et al., 2006). For both scales, higher scores, on a 1-5 scale, indicate greater competence. The orientation and engagement rating subscale measures a child's cooperation with the interviewer, positive affect, and interest in the test materials. The emotion regulation rating subscale measures a child's ability to change tasks and test materials, negative affect, and frustration with tasks during the assessment.

\section{Covariates}

\section{Household composition}

Composition was coded, per Chazan-Cohen et al., 2007, so that married two-parent households $=1$, other adults in the home $=2$, and single parents $=3$. In this study, 674 women (26\%) reported they were married; 1,038 women (39\%) reported they lived with other adults (including children's grandparents); and 915 women (35\%) reported they lived with no other adults.

\section{Cumulative risk}

The cumulative risk index is a composite variable of risk indicators. Indicators of risk were as follow: parental education (no high school diploma), age at birth of first child (teen parenthood), unemployment, single parenthood, and receipt of welfare. Variables were dummy coded and summed. In the current study, mothers had a mean of 2.65 risks $(S D=1.15 ; \min =.00 ; \max =5.00)$.

\section{Program status}

Program status indicates whether a family received the EHS intervention, which has been shown to positively impact child- and parent-level outcomes (Love et al., 2005). The PA construct did not differentially predict children's social-emotional development according to the chi-square difference based on a two-group (program status) structural equation model.

\section{Child emotionality}

Child emotionality, a temperamental characteristic, was assessed at the 14-month birthday-related assessment, using the Emotionality subscale $(\alpha=.72 ; 5$ items $)$ of the parent-reported Emotionality, Activity, Sociability, and Impulsivity Temperament Survey (Buss \& Plomin, 1984). Sample items include "He/She often fusses and cries" and "He/she cries easily." 


\section{Data Analysis}

Structural equation modeling (SEM) via LISREL 8.8 was utilized with criteria for fit indices according to $\mathrm{Hu}$ and Bentler (1999) and Browne and Cudeck (1993). Covariates were freed to predict all endogenous latent factors. Effect sizes are reported via the standardized path coefficients (see Figure 1) and the squared multiple correlations of the latent factors. Only significant paths are represented in Figure 1, although all covariates were freed to predict throughout the model.

Holmbeck's (1997) for testing mediation within SEM were employed as follows: (1) good model fit for the complete model; (2) good model fit when constraining to zero the path between $\mathrm{X}$ and $\mathrm{M}$ and the path between $\mathrm{M}$ and $\mathrm{Y}$, only estimating the direct effect; and (3) no improvement in model fit for the complete model when only the direct effect is constrained to zero.

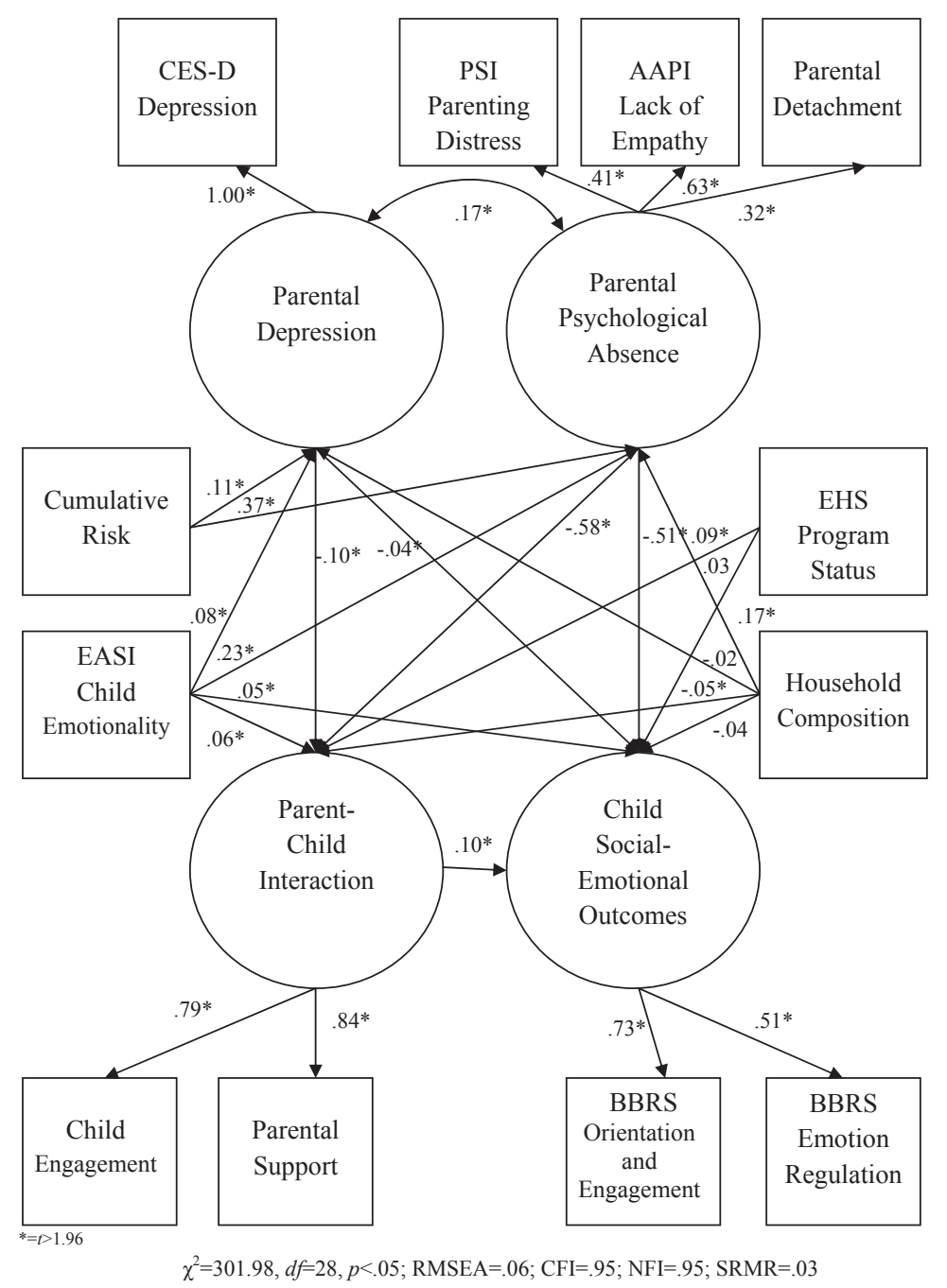

FiguRE 1. Associations between psychological absence and children's sociol-emotional development, mediated by positive parent-child interaction. $\chi^{2}=301.98, d f=28, p<.05$; RMSEA $=.06$;

$\mathrm{CFI}=.95 ; \mathrm{NFI}=.95 ; \mathrm{SRMR}=.03$.

Fam. Proc., Vol. 51, December, 2012 


\section{RESULTS}

Analyses indicated that the hypothesized model fit the data (see Figure 1). Factor loadings demonstrated a reasonable fit for the PA latent factor. PA was associated with depressive symptoms $(\beta=.17)$. Examination of the correlation matrix suggests there are mixed relationships between parental distress, lack of empathy, and detachment and maternal depression; the strongest association is between parental distress and maternal depression $(r=.39, p<.01)$.

Psychological absence significantly negatively predicted mother-toddler interaction quality $(\beta=-.58)$ and toddlers' social-emotional outcomes $(\beta=-.51)$, demonstrating large effect sizes. Although maternal depressive symptoms also significantly negatively predicted mother-toddler interaction quality $(\beta=-.10)$ and toddlers' outcomes $(\beta=-.04)$, the effect sizes were smaller than those for relations between PA and child outcomes. The model's effect sizes in predicting both mother-child interaction $\left(R^{2}=.33\right)$ and child socialemotional outcomes $\left(R^{2}=.32\right)$ were robust. Parent-child interactions partially mediated relations between depressive symptoms and child social-emotional outcomes, and relations between PA and child outcomes.

\section{DISCUSSION}

Findings validated a PA construct which significantly predicted mother-child interaction and child outcomes, and, when correlated with depressive symptoms, predicted more variance in the endogenous factors than depressive symptoms alone. We will interpret the findings within a general BA framework to explain the impacts of PA on toddlers' social-emotional outcomes.

The caregiving behavioral system, defined as the parent's internal working model that motivates behavior to provide care to one's child, is a subjective and internal system of experiences and is reciprocal to the child's attachment system (Solomon \& George, 2008). The parent-child relationship is a unique family subsystem, and requires unique measurement methods accounting for the parent's internal experiences. Pursuant to BA theory, the complete model suggests that maternal PA likely indicates limited resources within the mother-child relationship to help children make sense of discontinuities, leading to children's poor social-emotional outcomes (Boss, 2006). Results were robust even when maternal depression was included in the model-an important finding given the well-known associations between maternal depression and children's outcomes.

The degree of BA in a family system is moderated by the parent's ability to contribute to the family's coping abilities (Buehler \& Pasley, 2000). Children experiencing BA in their relationships with their parents might experience the primary effects of the PA and secondary effects of limited family-level coping strategies because the psychologically absent member of the family is the primary caregiver. Emotion regulation and positive engagement are likely related to effective coping strategies (Eisenberg \& Spinrad, 2004). Emotion regulation is a key element in social-emotional development, and predictable support from the parent contributes to the healthy development of regulatory competencies (Cole, Martin, \& Dennis, 2004).

The role of the parent-child relationship in early emotional development, particularly with regard to mutual regulatory processes, is well-known (Beebe \& Lachmann, 1998; Osofsky \& Thompson, 2000). Bowlby (1969, 1973, 1980) posited that separation from one's primary caregiver predicted less optimal psychosocial development. The current study builds on this scholarship, defining similar sensitive outcomes for children when these shared processes are unavailable due to maternal PA, although the caregiver incongruently physically maintains the role of primary caregiver. Likewise, these disruptions likely interrupt the shared meaning making, informed by attachment theory, between parent 
and child who are critical to the parent-child relationship as a context for children's acquisition of social-emotional competencies.

The covariates were significant predictors of some of the major outcome factors, with moderate effect sizes. It is reasonable to expect program participation to predict some of the variance in outcomes in positive parent-child interaction, as has been the case in previous research (Chazan-Cohen et al., 2007; Love et al., 2005). Hence, the significance of EHS program participation in this model suggests the importance of considering the ways an intervention might improve outcomes for parents and children. Furthermore, results show that living arrangements had an impact on the tested outcomes, suggesting that residential social support may contribute to better interactions between mothers and young children. Other research supports this finding insofar as mothers who receive support from other adults who are able to help provide care for children may experience less depressive symptoms and greater parenting competence (Morris, Silk, Steinberg, Myers, \& Robinson, 2007; Silver, Heneghan, Bauman, \& Stein, 2006).

Regarding child emotionality, children with greater emotionality in infancy have mothers with more depressive symptomatology and who were more psychologically absent, but these children also experienced between parent-child interactions and demonstrated more optimal social-emotional outcomes. Other research presents mixed findings regarding the relationship between infant temperament and maternal responsiveness (Crockenberg \& Leerkes, 2003; Crockenberg \& Smith, 2002; Cutrona \& Troutman, 1986). The current study suggests that, within a BA framework, children who are fussier may be more consistently initiating parent-child interactions which include sensitivity and thus contributing to a shared repertoire of predictable interactions, the basis for clear relational boundaries.

\section{Limitations}

Further work is needed to replicate this construct in other data sets and to more concretely examine its relationship with BA. PA factor loadings suggest that this study represents a reasonable starting point, given the moderate to high amounts of variance the variables explain in the latent construct. However, given the mixed correlations between the manifest variables indicating psychological absence and maternal depression, as well as the relatively small correlation between the latent factor and maternal depression, combined with the significant amount of unexplained variance in the latent factor, there may be other potentially superior ways to measure this construct. The stronger relations between PA and parent-child interaction as compared with that between depressive symptoms and parent-child interaction may reflect shared method variance. Furthermore, the restricted range of the observation variables may indicate limited interindividual variance. In addition, this model does not account for the quality of the contributions made by fathers, grandmothers, and other caregivers, beyond their presence; warm, secure relationships with these other caregivers may buffer the effects of PA. Finally, this study is limited as a secondary analysis with regard to the selection and operationalization of study variables, and, in particular, a more comprehensive battery of social-emotional outcomes would have been beneficial.

Study results indicate that PA may be an important construct for interventions to address, and the measurement of a proximal construct provides guidance for the ways in which PA might manifest in the early parent-child relationship.

\section{Clinical Implications}

Our findings indicate that psychological absence as a metaconstruct is theoretically and empirically consistent in a sample of low-income mothers and their toddlers. The 
metaconstruct of PA helps to define the context in which known interrelated variables (parenting stress, lack of empathy, maternal detachment, maternal depression) impact family-level functioning. There have been continued calls for theoretically driven intervention programs in support of healthy child and family development (e.g., Moss et al., 2011; Gonzalez \& MacMillan, 2008). Certainly a majority of home visiting programs, for example, identify promoting positive parenting and optimal parent-child interactions as key goals (Sweet and Appelbaum, 2004). However, home visitors themselves report that not only do parents with mental illness provide immense challenges to them but that they often feel lacking in the clinical skills, experience, and training to address such challenging circumstances in their work with parents (LeCroy \& Whitaker, 2005). Examining the relationships among the variables in this study in this way, from the perspective of BA theory, provides a useful understanding of the ways in which ambiguity informs and inhibits coping processes, therefore providing a concrete treatment planning goal (i.e., meaning making) beyond the general framework of supporting improved interactions between mothers and children. Examples of meaning making might include helping families define family role boundaries and responsibilities (i.e., concretely helping women define the role of mothering), contributing to more predictable interactions between mothers and children.

\section{REFERENCES}

Abidin, R.R. (1995). Parenting Stress Index (3rd ed.). Odessa, FL: Psychological Assessment.

Ackerman, J.P., \& Dozier, M. (2005). The influence of foster parent investment on children's representations of self and attachment figures. Journal of Applied Developmental Psychology, 26(5), 507-520.

Ainsworth, M.S. (1969). Maternal Sensitivity Scales. Baltimore, MD: Johns-Hopkins University.

Anthony, L., Anthony, B., Glanville, D., Naiman, D., Waanders, C., \& Shaffer, S. (2005). The relationships between parenting stress, parenting behavior, and preschoolers' competence and behaviour problems in the classroom. Infant and Child Development, 14, 133-154.

Aronson, S.R., \& Huston, A.C. (2004). The mother-infant relationship in single, cohabiting, and married families: A case for marriage? Journal of Family Psychology, 18(1), 5-18.

Ashman, S.B., Dawson, G., \& Panagiotides, H. (2008). Trajectories of maternal depression over 7 years: Relations with child psychophysiology and behavior and role of contextual risks. Development and Psychopathology, 20, $55-77$.

Bavolek, S. (1984). Handbook for the adult-adolescent parenting inventory. Park City, UT: Family Development Resources, Inc.

Bavolek, S.J. (1989). Assessing and treating high-risk parenting attitudes. Early Child Development and Care, 42(1), 99-112.

Bayley, N. (1993). Bayley scales of infant development: Manual (2nd ed.). New York: Harcourt.

Beebe, B., \& Lachmann, F.M. (1998). Co-constructing inner and relational processes: Self and mutual regulation in infant research and adult treatment. Psychoanalytic Psychology, 15(4), 480-516.

Belsky, J., \& Fearon, R.M.P. (2002). Early attachment security, subsequent maternal sensitivity, and later child development: Does continuity in development depend upon continuity of caregiving? Attachment \& Human Development, 4(3), 361-387.

Bocknek, E.L., Sanderson, J., \& Britner, P.A. (2009). Ambiguous loss and post-traumatic stress in school-age children of prisoners. Journal of Child and Family Studies, 18(3), 323-333.

Bornstein, M., \& Tamis-LeMonda, C. (2004). Mother-infant interaction. In G. Bremner \& A. Fogel (Eds.), Blackwell handbook of infant development (pp. 269-295). Malden, MA: Blackwell.

Boss, P. (1977). A clarification of the concept of psychological father presence in families experiencing ambiguity of boundary. Journal of Marriage and the Family, 39, 141-151.

Boss, P. (2004). Ambiguous loss research, theory and practice: Reflections after 9/11. Journal of Marriage and Family, 66, 551-566.

Boss, P. (2006). Loss, trauma, and resilience: Therapeutic work with ambiguous loss. New York: W.W. Norton.

Boss, P. (2007). Ambiguous loss theory: Challenges for scholars and practitioners. Family Relations: Special issue on ambiguous loss, $56,105-111$.

Boss, P., Caron, W., Horbal, J., \& Mortimer, J. (1990). Predictors of depression in caregivers of dementia patients: Boundary ambiguity and mastery. Family Process, 29, 245-254. 
Boss, P., \& Greenberg, J. (1984). Family boundary ambiguity: A new variable in family stress theory. Family Process, $23,535-546$.

Boss, P., Greenberg, J., \& Pearce-McCall, D. (1990). Measurement of boundary ambiguity in families. Station Bulletin (593-1990). Minneapolis: University of Minnesota.

Bowlby, J. (1969, 1973, 1980). Attachment and loss (Vol. 1-3). New York: Basic Books.

Browne, M.W., \& Cudeck, R. (1993). Alternative ways of assessing model fit. In K. Bollen \& J. Long (Eds.), Testing structural equation models (pp. 136-162). Beverly Hills, CA: Sage.

Brownell, C.A., \& Kopp, C.B. (2007). Transitions in toddler social-emotional development: Behavior, understanding, relationships. In C.A. Brownell \& C.B. Kopp (Eds.), Social-emotional development in the toddler years (pp. 1-42). New York, NY: Guildford.

Buehler, C., \& Pasley, K. (2000). Family boundary ambiguity, marital status, and child adjustment. Journal of Early Adolescence, 20(3), 281-308.

Buss, A.H., \& Plomin, R. (1984). Temperament: Early developing personality traits. Hillsdale, NJ: Erlbaum.

Campbell, S.B., Brownell, C.A., Hungerford, A.H., Spieker, S.J., Mohan, R., \& Blessing, J.S. (2004). The course of maternal depressive symptoms and maternal sensitivity as predictors of attachment security at 36 months. Development and Psychopathology, 16, 231-252.

Carroll, J.S., Olson, C.D., \& Buckmiller, N. (2007). Family boundary ambiguity: A 30-year review of theory, research, and measurement. Family Relations: Special issue on ambiguous loss, 56, 210-2302.

Chazan-Cohen, R., Ayoub, C., Pan, B.A., Roggman, L., Raikes, H., McKelvey, L. et al. (2007). It takes time: Impacts of Early Head Start that lead to reductions in maternal depressive symptoms two years later. Infant Mental Health Journal: Special issue on Early Head Start, 28(2), 151-170.

Cole, P.M., Martin, S.E., \& Dennis, T.A. (2004). Emotion regulation as a scientific construct: Methodological challenges and directions for child development research. Child Development, 75(2), 317-333.

Crockenberg, S.B., \& Leerkes, E. (2000). Infant social and emotional development in family context. In C.H. Zeanah (Ed.), Handbook of infant mental health (2nd ed., pp. 60-90). New York: Guilford Press.

Crockenberg, S.B., \& Leerkes, E. (2003). Infant negative emotionality, caregiving, and family relationships. In A.C. Crouter \& A. Booth (Eds.), Children's influence on family dynamics (pp. 57-78). Mahwah, NJ: Lawrence Erlbaum Associates, Inc.

Crockenberg, S.B., \& Smith, P. (2002). Antecedents of mother-infant interaction and infant irritability in the first 3 months of life. Infant Behavior and Development, 25(1), 2-15.

Cutrona, C.E., \& Troutman, B.R. (1986). Social support, infant temperament, and parenting self-efficacy: A mediational model of postpartum depressive symptoms. Child Development, 57, 1507-1518.

Deater-Deckard, K., Petrill, S.A., Thompson, L.A., \& DeThorne, L.S. (2005). A cross-sectional behavioral genetic analysis of task persistence in the transition to middle childhood. Developmental Science, 8(3), 21-26.

Dempster, A.P., Laird, N.M., \& Rubin, D.B. (1977). Maximum likelihood estimation from incomplete data via the EM algorithm. Journal of the Royal Statistical Society, Series B, 39, 1-38.

Dudgeon, P. (2003). NIESEM: A computer program for calculating noncentral interval estimates (and power analysis) for structural equation modeling. Melbourne, Australia: Department of Psychology, University of Melbourne.

Eisenberg, N., \& Spinrad, T.L. (2004). Emotion related regulation: Sharpening the definition. Child Development, $75,334-339$.

Enders, C.K. (2006). Analyzing structural equation models with missing data. In G.R. Hancock \& R.O. Mueller (Eds.), Structural equation modeling: A second course (pp. 313-342). Greenwich, CT: Information Age Publishing.

Feldman, R., Granat, A., Pariente, C., Kanety, H., Kuint, J., \& Gilboa-Schechtman, E. (2009). Maternal sepression and anxiety scross the postpartum year and infant social engagement, fear regulation, and stress reactivity. Journal of the American Academy of Child and Adolescent Psychiatry, 48(9), 919-927.

Feng, X., Shaw, D.S., Kovacs, M., Lane, T., O’Rourke, F.E., \& Alarcon, J.H. (2008). Emotion regulation in preschoolers: The roles of behavioral inhibition, maternal affective behavior, and maternal depression. Journal of Child Psychology and Psychiatry, 49(2), 132-141.

Field, T. (2010). Postpartum depression effects on early interactions, parenting, and safety practices: A review. Infant Behavior and Development, 33(1), 1-6.

Focht-Birkerts, L., \& Beardslee, W.R. (2000). A child's experience of parental depression: Encouraging relational resilience in families with affective illness. Family Process, 39(4), 417-434.

Foster, C.J.E., Garber, J., \& Durlak, J.A. (2008). Current and past maternal depression, maternal interaction behaviors, and children's externalizing and internalizing symptoms. Journal of Abnormal Child Psychology, $36,527-537$.

Gonzalez, A., \& MacMillan, H.L. (2008). Preventing child maltreatment: An evidence-based update. Journal of Postgraduate Medicine, 54(4), 280-286. 
Goodman, S.H., Rouse, M.H., Connell, A.M., Broth, M.R., Hall, C.M., \& Heyward, D. (2011). Maternal depression and child psychopathology: A meta-analytic review. Clinical Child and Family Psychology Review, 14(1), 1-27.

Holmbeck, G.N. (1997). Toward terminological, conceptual, and statistical clarity in the study of mediators and moderators: Examples from the child-clinical and pediatric psychology literatures. Journal of Consulting and Clinical Psychology, 65, 599-610.

Hu, L., \& Bentler, P.M. (1999). Cutoff criteria for fit indexes in covariance structure analysis: Conventional criteria versus new alternatives. Structural Equation Modeling, 6, 1-55.

Kiernan, K.E., \& Huerta, M.C. (2008). Economic deprivation, maternal depression, parenting and children's cognitive and emotional development in early childhood. The British Journal of Sociology, 59(4), 783-806.

Kochanska, G. (2001). Emotional development in children with different attachment histories: The first three years. Child Development, 72(2), 474-490.

Lavee, Y., McCubbin, H.I., \& Patterson, J.M. (1985). The Double ABCX Model of family stress and adaptation: An empirical test by analysis of structural equations with latent variables. Journal of Marriage and the Family, 47(4), 811-825.

Leckman-Westin, E., Cohen, P.R., \& Stueve, A. (2009). Maternal depression and mother-child interaction patterns: Association with toddler problems and continuity of effects into late childhood. Journal of Child Psychology and Psychiatry, 50(9), 1176-1184.

Lecroy, C.W., \& Whitaker, K. (2005). Improving the quality of home visitation: An exploratory study of difficult situations. Child Abuse \& Neglect, 29, 1003-1013.

Leigh, B., \& Milgrom, J. (2008). Risk factors for antenatal depression, postnatal depression and parenting stress. BMC Psychiatry, 8(1), 24.

Lieberman, A.F., \& Van Horn, P. (2009). Child-parent psychotherapy: A developmental approach to mental health treatment in infancy and early childhood. In C.H. Zeanah (Ed.), Handbook of infant mental health, (3rd ed., pp. 439-449). New York, NY: Guilford Press.

Love, J.M., Kisker, E.E., Ross, C., Raikes, H., Constantine, J., Boller, K. et al. (2005). The Effectiveness of Early Head Start for 3-year-old children and their parents: Lessons for policy and programs. Developmental Psychology: Special section on the effectiveness of Early Head Start, 41(6), 885-901.

Lovejoy, M.C., Graczyk, P.A., O’Hare, E., \& Neuman, G. (2000). Maternal depression and parenting behavior: A meta-analytic review. Clinical Psychology Review, 20(5), 561-592.

MacCallum, R.C., Browne, M.W., \& Sugawara, H.M. (1996). Power analysis and determination of sample size for covariance structure. Psychological Methods, 1(2), 130-149.

Madden-Derdich, D.A., \& Arditti, J.A. (1999). The ties that bind: Attachment between former spouses. Family Relations, 48, 243-249.

Maughan, A., Cicchetti, D., Toth, S.L., \& Rogosch, F.A. (2007). Early-occurring maternal depression and maternal negativity in predicting young children's emotion regulation and socioemotional difficulties. Journal of Abnormal Child Psychology, 35, 685-703.

Morris, A.S., Silk, J.S., Steinberg, L., Myers, S.S., \& Robinson, L.R. (2007). The role of the family context in the development of children's emotion regulation. Social Development, 16, 361-388.

Moss, E., Dubois-Comtois, K., Cyr, C., Tarabulsy, G.M., St-Lauren, D., \& Bernier, A. (2011). Efficacy of a homevisiting intervention aimed at improving maternal sensitivity, child attachment, and behavioral outcomes for maltreated children: A randomized control trial. Development and Psychopathology, 2(1), 195-210.

Osofsky, J.D., \& Thompson, M.D. (2000). Adaptive and maladaptive parenting: Perspectives on risk and protective factors. In J.P. Shonkoff \& S.J. Meisels (Eds.), Handbook of early childhood intervention (2nd ed., pp. 5475). New York: Cambridge University Press.

Peden, A.R., Rayens, M.K., Hall, L.A., \& Grant, E. (2004). Negative thinking and the mental health of low-income single mothers. Journal of Nursing Scholarship, 36, 337-344.

Radloff, L.S. (1977). The CES-D scale: A self-report depression scale for research in the general population. Journal of Applied Psychological Measurement, 1, 385-401.

Raikes, H., Pan, B., Luze, G., Tamis-LeMonda, C., Brooks-Gunn, J., Constantine, J. et al. (2006). Mother-child bookreading in low-income families: Correlates and outcomes during the first three years of life. Child Development, 77(4), 924-953.

Raikes, A., Robinson, J.L., Bradley, R.H., Raikes, H.H., \& Ayoub, C.C. (2007). Developmental trends in self regulation among low-income toddlers. Social Development, 16(1), 128-149.

Rogers, S.J., \& White, L.K. (1998). Satisfaction with parenting: The role of marital happiness, family structure, and parents' gender. Journal of Marriage and the Family, 60, 293-308.

Rosenberg, M., \& Guttmann, J. (2001). Structural boundaries of single-parent families and children's adjustment. Journal of Divorce \& Remarriage, 36(1-2), 83-98.

Ross, C.E., Mirowsky, J., \& Huber, J. (1983). Dividing work, sharing work, and in-between: Marriage patterns and depression. American Sociological Review, 52, 1059-1078. 
Rothbart, M.K., \& Derryberry, D. (1981). Development of individual differences in temperament. In M.E. Lamb \& A.L. Brown (Eds.), Advances in developmental psychology (Vol. 1, pp. 37-86). Hillsdale, NJ: Erlbaum.

Schafer, J.L., \& Graham, J.W. (2002). Missing data: Our view of the state of the art. Psychological Methods, 7(2), $147-177$.

Silver, E., Heneghan, A., Bauman, L., \& Stein, R. (2006). The relationship of depressive symptoms to parenting competence and social support in inner-city mothers of young children. Maternal \& Child Health Journal, 10, 105-112.

Solomon, J., \& George, C. (2008). The caregiving system: A behavioral systems approach to parenting. In J. Cassidy \& P.R. Shaver (Eds.), Handbook of attachment: Theory, research, and clinical applications (2nd ed., pp. 833-856). New York: Guilford Press.

Stein, A., Gath, D.H., Bucher, J., Bond, A., Day, A., \& Cooper, P.J. (1991). The relationship between post-natal depression and mother-child interaction. The British Journal of Psychiatry, 158, 46-52.

Sterba, S.K., Prinstein, M.J., \& Cox, M.J. (2007). Trajectories of internalizing problems across childhood: Heterogeneity, external validity, and gender differences. Development and Psychopathology, 19(02), 345-366.

Sweet, M.A., \& Appelbaum, M.I. (2004). Is home visiting an effective strategy? A meta-analytic review of home visiting programs for families with young children. Child Development, 75, 1435-1456.

Taanila, A., Laitinen, E., Moilanen, I., \& Jarvelin, M.J. (2002). Effects of family interaction on the child's behavior in single parent or reconstructed families. Family Process, 41(4), 693-708.

Thomas, A., \& Chess, S. (1977). Temperament and development. New York: Brunner/Mazel.

Thomas, P., Clément, J.P., Hazif-Thomas, C., \& Léger, J.M. (2001). Family, Alzheimer's disease and negative symptoms. International Journal of Geriatric Psychiatry, 16, 192-202.

Trevarthen, C., \& Aitken, K.J. (2001). Infant intersubjectivity: Research, theory, and clinical applications. Journal of Child Psychology and Psychiatry, 42, 3-48.

Vogel, C.A., Bradley, R.H., Raikes, H.H., Boller, K., \& Shears, J.K. (2006). Relations between father connectedness and child outcomes. Parenting, 6(2-3), 189-209. doi:10.1080/15295192.2006.9681305 